\title{
析出核生成による自由エネルギーの第一原理計算
}

\author{
世古敦人 1,* $^{*}$ 西谷滋 ${ }^{2} \quad$ 田中 $\quad$ 功 $^{1} \quad$ 足立裕彦 3
}

\author{
1京都大学工学研究科材料工学専攻 \\ 2関西学院大学理工学部情報科学科 \\ 京都大学名誉教授
}

J. Japan Inst. Metals, Vol. 68, No. 12 (2004), pp. 973-976

Special Issue on Computer Aided Phase Diagram Assessment and Its Extension to Materials Design

C 2004 The Japan Institute of Metals

\section{First Principles Calculation of Free Energy on Precipitate Nucleation}

\author{
Atsuto Seko ${ }^{1 *}$, Shigeto R Nishitani ${ }^{2}$, Isao Tanaka ${ }^{1}$ and Hirohiko Adachi ${ }^{3}$ \\ ${ }^{1}$ Department of Materials Science and Engineering, Kyoto University, Kyoto 606-8501 \\ ${ }^{2}$ Department of Informatics, Kwansei University, Sanda 669-1337 \\ ${ }^{3}$ Professor Emeritus of Kyoto University, Kyoto 606-8501
}

We developed the method to calculate free energy of precipitate nucleation. This method divides the free energy into the cluster energy and entropy terms. The former, consisting of the enthalpy of driving force and the interface energy, is precisely calculated by first-principles calculations. The latter, which is entropy loss from scattered atoms condensing into a cluster, is estimated by the ideal solution model. Model calculations have been performed for an $\mathrm{Fe}-\mathrm{Cu}$ alloy, $\mathrm{Ni}$ added $\mathrm{Fe}-\mathrm{Cu}$ alloy, and vacancy behavior around $\mathrm{Cu}$ clusters.

(Received July 20, 2004; Accepted September 15, 2004)

Keywords: first principles calculation, precipitate nucleation, activation energy, critical number, iron-copper, vacancy

1.は じめ に

状態図の重要な利用分野の一つに析出過程がある。仕込み 組成と固相線，析出相の組成との比などに基づく，析出物の 量や大きさの制御は金属材料設計の基本である.しかし，そ の析出過程において, 核生成の自由エネルギ一変化に活性化 の山が存在しないのではないかという疑問が 1970 年代から 藤田によって投げ掛けられている11.

古典的核生成論は，相転移において新相のエンブリオが核 として成長する前段階では系のエネルギ一は正となり，それ を超えるための活性化過程があるとする. エンブリオを半径 rの球状として，そのエネルギーを表現する式，

$$
\Delta G=-\frac{4}{3} \pi r^{3} \varepsilon+4 \pi r^{2} \gamma
$$

において，rが小さいと $r^{2}$ を含む表面エネルギー $\gamma$ による右 辺第二項が $\gamma^{3}$ を含む体積エネルギー $\varepsilon$ による第一項を優先 し, Fig. 1 に示すように, 成長初期には $\Delta G$ が上昇し, 核生 成は活性化過程をともなうとする.これに対する藤田のジレ ンマは, 界面エネルギーは析出物の体積エネルギーよりも小 さいはずであり, 古典的核生成論が述べているような理屈に よって活性化の山が出来るはずがないというものである ${ }^{21}$.

京都大学大学院生 (Graduate Student, Kyoto University) Corresponding author, E-mail: zeko@240z.mbox.media.kyoto-u.ac. jp

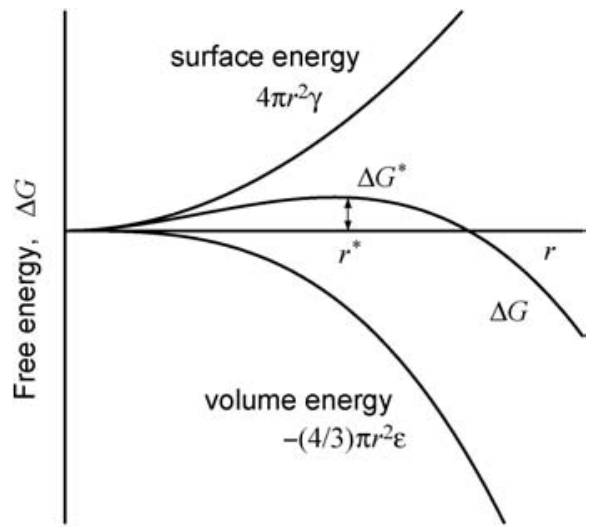

Fig. 1 Free energy in classical treatment.

著者らが調べた範囲において，この疑問に対して解答を与え た論文は見当たらない3).

本論文では, 著者らが開発した析出過程の自由エネルギー を求める第一原理計算法を紹介し, 藤田ジレンマへの解答を 試みる.ここでは実用材料として重要な $\mathrm{Fe}-\mathrm{Cu}$ 系の bcc- $\mathrm{Cu}$ の析出クラスターの自由エネルギー変化の起源, 第三元素添 加の影響を第一原理計算から明らかにする.

\section{2. 核生成自由エネルギーの計算手法}

古典的核生成理論において, クラスター形成による自由エ 
ネルギー変化は, 前述のとおりクラスター体積 (半径の 3 乗, あるいは原子数 $n$ の 1 乗) に比例する駆動力 $\Delta F_{\mathrm{V}}$ と, クラスター表面積 (半径の 2 乗, あるいは原子数の $2 / 3$ 乗) に比例する界面エネルギー $H_{\sigma}$ の和で表される. 本論文で は, 前者の駆動力をエンタルピー項 $\Delta H_{\mathrm{V}}$ とエントロピー項 - T $\Delta S_{\mathrm{V}}$ に分割し, エンタルピー変化と界面エネルギーを同 時に取り扱う. そのようにくくると, 自由エネルギー変化は,

$$
\Delta F(n)=\left(\Delta H_{\mathrm{V}}(n)+H_{\sigma}(n)\right)-T \Delta S_{\mathrm{V}}(n)
$$

\section{と表現される.}

式 ( 2 )のような自由エネルギー表式は, 上条・福富らに よって初めて提案された ${ }^{4)}$. 右辺第 1 項はクラスターエネル ギー変化であり, 溶質原子や溶媒原子の結合変化によるエン タルピー変化と界面エネルギーから成り立つ.このクラス ターエネルギー変化は温度に依存しないものと仮定した場 合, 密度汎関数理論に基づいた精密計算が可能である. また 格子のミスフィットによる歪エネルギーは, 格子緩和を考慮 した第一原理計算によりクラスターエネルギーに含まれる. 式 ( 2 )の右辺第 2 項は, 配置のエントロピー変化であり,
Initial state

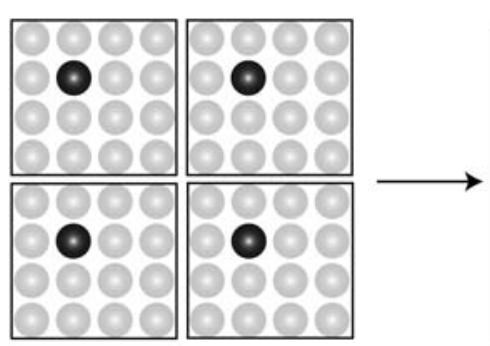

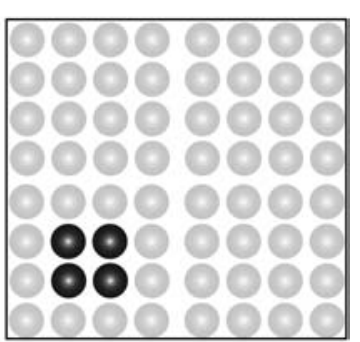

Final state
Fig. 2 Initial and final states of the precipitate nucleation process.
理想溶体近似による見積もりが可能で，

$$
\Delta S_{\mathrm{V}}(n)=k_{\mathrm{B}}(n-1) \ln (x)
$$

と表記される ${ }^{4)}$. ここで， $k_{\mathrm{B}}$ は Boltzmann 定数， $x$ は初期溶 質濃度である.

このような核生成の自由エネルギ一計算は, 模式的に Fig. 2 に示したような始状態と終状態を考えていることに相 当する. Fig. 2 において, 核生成の始状態は母相中に溶質原 子が抢互いに相互作用する事なく分散した状態であり, 希薄 極限に相当する. 一方, 核生成の終状態はサイズ $n$ のクラ スターが析出した状態で, バルク状態ではなくこの小さな原 子集団が持つエントロピーを考慮する必要がある. 核生成の 自由エネルギー変化はこの二つの状態のエンタルピー変化と エントロピー変化の和で表される. エンタルピー変化にはボ ンドの組み換えに伴う界面エネルギーも含をれる.

\section{3. $\mathrm{Fe}-\mathrm{Cu}$ 系への適用}

モデル計算として前章で述べた手法を $\mathrm{Fe}-\mathrm{Cu}$ 系に適用し た. クラスターエネルギー変化 $\Delta H_{\mathrm{V}}+H_{\sigma}$ の計算には密度汎 関数理論を用いた. プログラムコードには Vienna Ab Initio Simulation Package(VASP) ${ }^{5,6}$ )を用いた. ウルトラソフト擬 ポテンシャル ${ }^{7)}$, 平面波基底, スピン分極考慮のもとで, 交 換相関ポテンシャルとして GGA (Perdew-Wang 91) 8) を用 いた。計算により求めた格子定数は bcc-Fe が $0.287 \mathrm{~nm}$, bcc-Cu が $0.290 \mathrm{~nm}$ であった. さらにクラスターエネル ギーの計算において, 歪エネルギーを取り入れるため, 格子 緩和を行った．計算に用いた周期的境界条件の supercell サ イズはクラスター間の相互作用をできるだけ小さくするた め, クラスターサイズが 1 から 5 原子のとき $3 \times 3 \times 3(54$ 原 子), 6 から 16 原子のとき $4 \times 4 \times 4$ (128 原子) とした． また

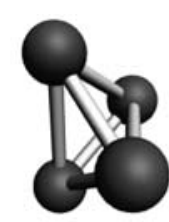

$n=4$

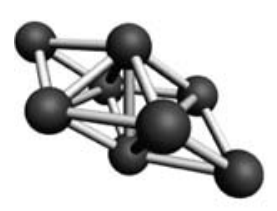

$n=8$

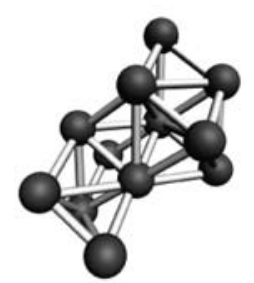

$n=12$

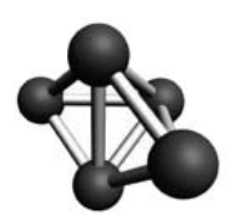

$n=5$

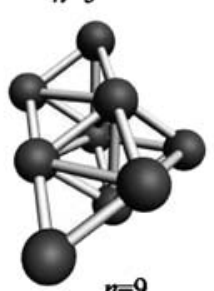

$n=9$

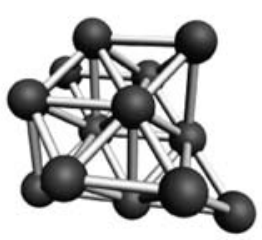

$n=13$

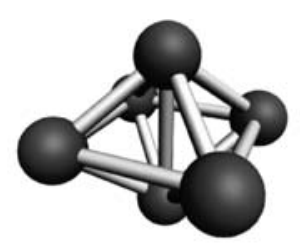

$n=6$

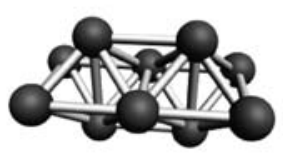

$n=10$

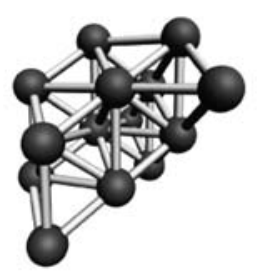

$n=14$

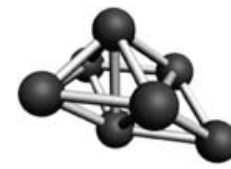

$n=7$

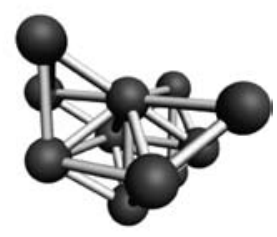

$n=11$

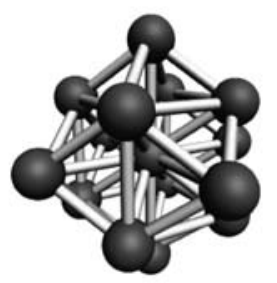

$n=15$

Fig. 3 Atomic configurations of the cluster for the minimum energy at a specific cluster size $n$. 
quasi-harmonic 近似において, 有限温度における始状態と 終状態の振動の自由エネルギー差は非常に小さいことか $ら^{9)}$, 有限温度効果として配置のエントロピーのみを考慮し た.モデルとした Fe-rich な $\mathrm{Fe}-\mathrm{Cu}$ 系では, 過飽和固溶体 からの核生成初期段階に抢いて, 準安定な bcc 構造の球状 $\mathrm{Cu}$ クラスターが析出し, 整合界面を持つことが報告されて いる10)ことから, bcc- $\mathrm{Fe}$ の一部のサイトを $\mathrm{Cu}$ 原子に置き 換え，モデルを構築した.

考えられるクラスターの原子配置の中で, エネルギーが最 小であるクラスターの形状を Fig. 3 に示す. またその配置 に対応する segregation limit からのクラスターエネルギー を Fig. 4 に示す. Fig. 4 における直線は dilution limit での エンタルピーを外挿したものであり, Fig. 2 における始状態 を表す。また終状態は closed-circleであるので, 式 (2)に 掞けるクラスターエネルギー変化は closed-circle と直線の 差である。

自由エネルギー変化はこのクラスターエネルギーとエント ロピー変化の和で表される. 古典的な取り扱い10) と比較す るため, $773 \mathrm{~K}, 1.4 \mathrm{at} \% \mathrm{Cu}$ においてエントロピー変化を見 積もった. 計算した自由エネルギー変化を Fig. 5 に示す.

Fig. 5 より, 配置のエントロピーの減少によって活性化エネ ルギーが生じるという知見が得られた. また求められた臨界 原子数と活性化エネルギーはそれぞれ 13 原子， $1.07 \times 10^{-19}$ $\mathrm{J}(0.67 \mathrm{eV})$ であった。これらは古典的取り扱い10)によって求 めた臨界原子数 13 原子, 活性化エネルギー $0.96 \times 10^{-19} \mathrm{~J}$

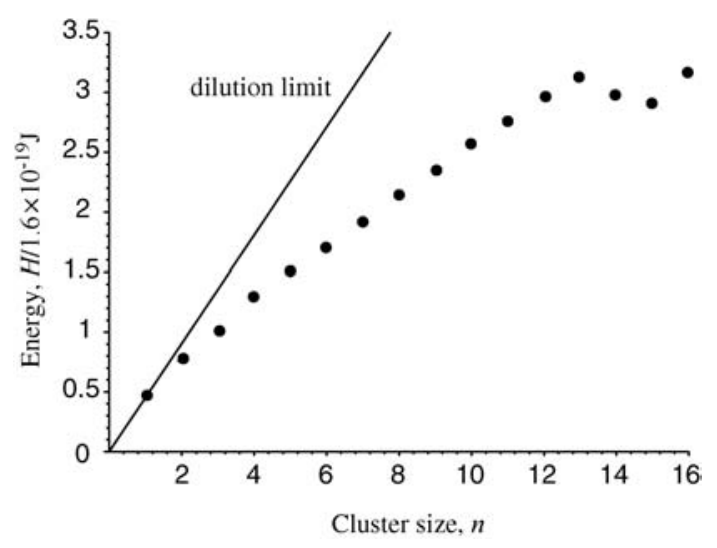

Fig. 4 Cluster energies measured from segregation limit.

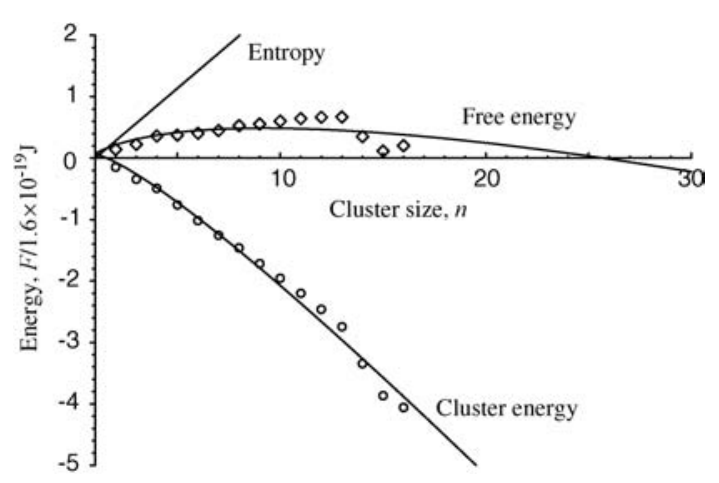

Fig. 5 Free energy change of precipitate nucleation in $\mathrm{Fe}-\mathrm{Cu}$ system $(773 \mathrm{~K}, 1.4 \mathrm{at} \% \mathrm{Cu})$.
$(0.6 \mathrm{eV})$ によく一致する. 次に古典的な取り扱いに打ける自 由エネルギーと比較するため, 界面エネルギーを一定である と仮定し, クラスターエネルギーを次式でフィッティングし た。

$$
\Delta H+H_{\sigma}=A n+B n^{2 / 3}
$$

ここで $A, B$ はフィッティングパラメータである.しかし, クラスターエネルギーはクラスター原子数 $n=1$ を基準とし ているので, $B=-A$ である. フィッティング曲線から見積 もられた界面エネルギーは $0.25 \mathrm{~J} / \mathrm{m}^{2}$ であり, 古典的取り扱 い10)の $0.4 \mathrm{~J} / \mathrm{m}^{2}$ より少し小さい. 第一原理計算によって求 めたスラブモデルの界面エネルギーは， $0.60 \mathrm{~J} / \mathrm{m}^{2}(\{001\})$, $0.24 \mathrm{~J} / \mathrm{m}^{2}(\{011\}), 0.34 \mathrm{~J} / \mathrm{m}^{2}(\{111\})$ であった. フィッティ

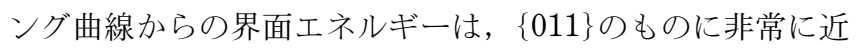
く,これはFig. 3 に示されているクラスターの界面がほと んど $\{011\}$ であることに一致する.

\section{3 元系への拡張}

次に $\mathrm{Fe}-\mathrm{Cu}-\mathrm{X}(\mathrm{X}=\mathrm{Ni}$ or vacancy) 3 元系を考える. 3 元 系において配置のエントロピーは,

$\Delta S_{\mathrm{V}} / k_{\mathrm{B}}=(n-1) \ln x_{\mathrm{Cu}}-n+\frac{3}{2} \ln n+\frac{1}{2} \ln (2 \pi)+\ln x_{\mathrm{X}}$ と記述される11).ここで, $x_{\mathrm{X}}$ はX $\mathrm{X}$ 初期濃度である. 濃度 とクラスターサイズが同じであるとしたとき, エントロピー は同じであるので, クラスターの原子配置はクラスターエネ ルギー変化 $\Delta H_{\mathrm{V}}+H_{\sigma}$ によって決定される.

そこで, クラスターの原子配置の簡単な比較として, $1 \mathrm{stNN}$ と $2 \mathrm{ndNN}$ の原子から成り, $\mathrm{Ni}$ 原子あるいは原子空 孔を 1 つ含む 15 原子のクラスターに拈いて, クラスターエ ネルギーを計算した．特徵的なモデルとして， Ni 原子ある いは原子空孔が (a)クラスターの中心にある場合, (b) 界面 にある場合，（c）母相中にある場合の3つを考えた。それぞ れの場合について計算したクラスターエネルギーを Table 1 に示す. $\mathrm{Ni}$ 原子の場合, クラスターエネルギーは (b) 界面に ある場合が最も低く, Ni 原子が母相/クラスター界面に偏析 することを示している。これは atom probe-field ion microscopy による比較的大きなサイズの析出物の観察の結 果 ${ }^{12)}$ と一致する。また核生成を考えたとき，（b)界面と（c) 母相の場合を比較すると, クラスターエネルギーが $0.94 \times$ $10^{-19} \mathrm{~J}(0.59 \mathrm{eV})$ 減少する.ささらに式( 5 ) より計算した 773 $\mathrm{K}, 1.4 \mathrm{at} \% \mathrm{Cu}, 0.5$ at $\% \mathrm{Ni}, 15$ 原子におけるエントロピーの減 少は $0.22 \times 10^{-19} \mathrm{~J}(0.14 \mathrm{eV})$ である. よってクラスターエネ ルギーとエントロピーの減少に伴い, 核生成の活性化エネル ギーが減少すると考えられる，これは Ni 添加によって析出

Table 1 Cluster energies at size of 15 including one $\mathrm{Ni}$ atom or vacancy. One Ni atom or a vacancy is located (a) at the center of the cluster, (b) at the matrix/cluster interface, and (c) in the matrix. (unit: $\mathrm{J}(\mathrm{eV})$ )

\begin{tabular}{cccc}
\hline & (a) & (b) & (c) \\
\hline $\mathrm{Ni}$ & $4.37 \times 10^{-19}(2.73)$ & $3.76 \times 10^{-19}(2.35)$ & $4.70 \times 10^{-19}(2.94)$ \\
\hline Vacancy & $1.23 \times 10^{-19}(0.77)$ & $1.95 \times 10^{-19}(1.22)$ & $2.70 \times 10^{-19}(1.69)$ \\
\hline
\end{tabular}


が促進されるという実験結果と一致する13).

次に，原子空孔の場合，(a)クラスターの中心にある場合 のクラスターエネルギーが最も低く，原子空孔は $\mathrm{Cu}$ 原子に 囲まれる傾向を持つ。これは陽電子消滅法による測定 ${ }^{14)}$ や，分子動力学法やモンテカルロ法によるシミュレーション 結果15,16) と一致する。さらに Niの場合と同様の理由によ り，活性化エネルギーが減少すると考えられる。しかし，原 子空孔の濃度の減少によって拡散係数が減少する可能性が考 えられ, 原子空孔導入による析出促進の起源は, この平衡エ ネルギーの計算だけからでは結論づけることはできない.

\section{5. を め}

$\mathrm{Fe}-\mathrm{Cu}$ 系は構成元素間のサイズ, 質量, 剛性率にほとん ど差がなく, 有限温度の振動エントロピーによる影響を無視 することが可能である. 藤田が考えていたボンドの変化によ るエネルギー変化は，ここでは cluster energy に相当する. そこでは確かに活性化エネルギーの山は存在せず, 単調に減 少する関数となっている. 山は, 分散した溶質原子がクラス ターへ凝集することによる配置エントロピーのロスによって 現れていることが明らかとなった。

本論文で述べた核生成自由エネルギーの計算手法は, 化学 的駆動力のエンタルピー項や界面エネルギーを第一原理計算 で精確に計算し, エントロピー変化を統計力学的手法によっ て解析的に求めている. これによって, 動的シミュレーショ ンではステップ数を極端に多くする必要のある, 熱平衡状態
の微妙な自由エネルギー変化に関連する，臨界半径や活性化 エネルギーの予測が可能となった．さらに適用範囲を拡げる 事によって，実験での観測が困難である，ナノサイズの系の 自由エネルギー変化や, 準安定相の析出過程が計算から求め る事が可能になる.

文献

1) E. F. Fujita: J. Mater. Sci. Soc. Jpn. 10 (1973) 105-111.

2) E. F. Fujita: The Problems of Defects Physics - Solve them and grasp the Nature!, editors, S. R. Nishitani, M. Aoki and S. Muto, (Yoshiokashoten, Japan, 2003) pp. 143-155.

3) E. i F. Fujita: J. JILM 53(2003) 224-230.

4) T. Kamijo and H. Fukutomi: Philos. Mag. A 48(1983) 685.

5) G. Kresse and J. Hafner: Phys. Rev. B 47(1993) 558.

6) G. Kresse and J. Furthmüller: Phys. Rev. B 54(1996) 11169.

7) D. Vanderbilt: Phys. Rev. B 41(1990) 7892.

8) J. P. Perdew and Y. Wang: Phys. Rev. B 45(1992) 13244.

9) K. Yuge, A. Seko, S. R. Nishitani and H. Adachi: Mater. Trans. 45 (2004) 1473-1477.

10) S. R. Goodman, S. S. Brenner and J. R. Jow Jr.: Metal. Trans. $4(1973) 2363$.

11) A. Seko, N. Odagaki, S. R. Nishitani, I. Tanaka and H. Adachi: Mater. Trans. 45 (2004) 1978-1981.

12) M. K. Miller, P. Pareige and M. G. Burke: Mater. Charact. $44(2000) 235$.

13) K. Osamura, H. Okuda, S. Ochiai, M.Takashima, K. Asano, M. Furusaka, K. Kishida and F. Kurosawa: ISIJ Int. 34(1994) 359

14) Y. Nagai, Z. Tang, M. Hasegawa, T. Kanai and M. Saneyasu: Phys. Rev. B 63(2001) 134110.

15) A. Takahashi, N. Soneda, S. Ishino and G. Yagawa: Phys. Rev. B 67 (2003) 024104.

16) N. Sonoda and T. Diaz de la Rubia: Philos. Mag. A 78(2003) 995. 